\title{
THE LEGISLATIVE INNOVATIONS IN THE REGULATION OF INVESTMENT TRANSACTIONS MADE USING THE FINANCIAL PLATFORM: EFFECTIVENESS EVALUATION ${ }^{1}$
}

\author{
Denis E. Matytsin \\ Volgograd State University, Volgograd, Russian Federation; \\ Volzhsky Branch of International Law Institute, Volzhsky, Russian Federation
}

\begin{abstract}
Introduction: the relevance of the paper is justified by the fact that the civil doctrine regarding the study of the topics of investment transactions made using the financial platform is in the stage of gradual formation. While academic economists are quite actively developing issues of forming new approaches to the remote provision of financial services to a wide range of consumers. The purpose of the study: the paper provides a detailed analysis of Federal Law of July 20, 2020, No. 211-FZ "On Making Financial Transactions Using the Financial Platform”, which entered into force in 2020 and regulates the activities of special legal entities - operators providing investment services to individuals. The aim is to evaluate the effectiveness of the provisions enshrined in Federal Law No. 211-FZ of July 20, 2020, "On Making Financial Transactions Using the Financial Platform". Analyzing the provisions of the newly adopted document, the author answers the question of whether they facilitate, accelerate and simplify the execution of transactions by a private investor made using the financial platform. The Rules of the financial platform are also analyzed as a legal regulatory basis for the entrepreneurial activity of the operator of the financial platform. Research methods: based on the materialistic worldview, the author uses a combination of general scientific and specific scientific methods. The main research methods are the logical and system-structural methods, the methods of induction and deduction, analysis and synthesis, as well as the formal legal method. Conclusions: it is concluded that the activity of recording data on financial transactions, which the repository (the registrar of financial transactions) must carry out according to Federal Law No. 211-FZ of 20.07.2020, is very cumbersome, complex, and costly, is subject to the risks of improper execution and improper preservation of personal data of consumers of financial services. It is proposed to use the depository and registration platform, which functions as a special electronic service on the website of the Bank of Russia, to record data on financial transactions using the financial platform. It is recommended to record the facts of financial transactions made in the system of a polysubject jurisdictional blockchain. The recommended scheme of polysubject blockchain interaction of entities operating on the territory of the Russian Federation has been developed, which allows each participant of the blockchain to simultaneously receive complete and reliable information on each stage of a financial transaction in the online mode and exclude irrational data transfer related to financial transactions and their participants, reduce the risk of improper storage of personal data of consumers of financial services, etc. It is proved that in Federal Law No. 211-FZ of 20.07.2020 the legislator has created a legal business scheme that is beneficial, first of all, for the operator of the financial platform - an intermediary organization. The amendments and additions to Federal Law No. 211-FZ of 20.07.2020 are proposed. The expediency of borrowing and integrating into the unified federal law "On Making Investment Transactions by Consumers in the Information and Telecommunications Network "Internet" all viable legislative provisions developed in Federal Law No. 211-FZ of 20.07.2020 is justified. This document also proposes to fix a set of rules for regulating remote digital transactions of investment in traditional financial assets, securities, digital financial assets, and derivative financial assets made by retail private investors (individuals) in the Internet $\vec{\delta}$ information and telecommunications network.

Key words: investment transactions, investment services, investor (consumer of financial services), information and telecommunications network "Internet", remote digital transactions, financial assets, financial platform, blockchain technologies.
\end{abstract}

Citation. Matytsin D.E. The Legislative Innovations in the Regulation of Investment Transactions Made Using the Financial Platform: Effectiveness Evaluation. Legal Concept = Pravovaya paradigma, 2021, vol. 20, no. 3, pp. 125-137. (in Russian). DOI: https://doi.org/10.15688/lc.jvolsu.2021.3.19 


\title{
ЗАКОНОДАТЕЛЬНЫЕ НОВЕЛЛЫ РЕГУЛИРОВАНИЯ ИНВЕСТИЦИОННЫХ СДЕЛОК, СОВЕРШАЕМЫХ С ИСПОЛЬЗОВАНИЕМ ФИНАНСОВОЙ ПЛАТФОРМЫ: ОЦЕНКА ЭФФЕКТИВНОСТИ ${ }^{1}$
}

\author{
Денис Евгеньевич Матыцин
}

Волгоградский государственный университет, г. Волгоград, Российская Федерация; Волжский филиал Международного юридического института, г. Волжский, Российская Федерация

\begin{abstract}
Введение: актуальность статьи обосновывается тем фактом, что цивилистическая доктрина в части исследования тематики инвестиционных сделок, совершаемых с использованием финансовой платформы, находится в стадии постепенного формирования. В то же время экономисты довольно активно разрабатывают вопросы формирования новых подходов к дистанционному предоставлению финансовых услуг широкому кругу потребителей. Цель исследования: в статье проводится детальный анализ Федерального закона от 20 июля 2020 г. № 211-Ф3 «О совершении финансовых сделок с использованием финансовой платформы», который вступил в силу в 2020 г. и регулирует деятельность особых юридических лиц - операторов, оказывающих частным лицам инвестиционные услуги. Преследуется цель оценки эффективности положений, закрепленных в Федеральном законе от 20 июля 2020 г. № 211-Ф3 «О совершении финансовых сделок с использованием финансовой платформы». Анализируя положения вновь принятого документа, автор отвечает на вопрос облегчают, ускоряют и упрощают ли они совершение частным инвестором сделок, совершаемых с использованием финансовой платформы. В качестве юридического регламентационного базиса предпринимательской деятельности оператора финансовой платформы анализируются также Правила финансовой платформы. Методы исследования: на базе материалистического мировоззрения автором применены в сочетании общенаучные и частнонаучные методы. Основными методами исследования выступают логический и системноструктурный методы, методы индукции и дедукции, анализа и синтеза, а также формально-юридический метод. Выводы: в заключении делается вывод о том, что деятельность по учету данных о финансовых сделках, которую репозитарий (регистратор финансовых транзакций) согласно Федеральномузакону от 20.07.2020№ 211-Ф3 должен осуществлять, весьма громоздкая, сложная и затратная, подвержена рискам ненадлежащего исполнения и ненадлежащего сохранения персональных данных потребителей финансовых услуг. Предлагается для учета данных о финансовых сделках с использованием финансовой платформы применять депозитарно-регистрационную платформу, функционирующую в качестве специального электронного сервиса на веб-сайте Банка России. Фиксацию фактов совершаемых финансовых сделок рекомендуется осуществлять в системе полисубъектного юрисдикционного блокчейна. Разработана рекомендованная схема полисубъектного блокчейн- взаимодействия субъектов, действующих на территории Российской Федерации, позволяющая каждому участнику блокчейна одновременно получать полную и достоверную информацию по каждому этапу совершаемой финансовой сделки в режиме онлайн и исключить нерациональную передачу данных, касающихся финансовых сделок и их участников, снизить риск ненадлежащего сохранения персональных данных потребителей финансовых услуг и т. д. Доказано, что законодатель в Федеральном законе от 20.07.2020 № 211-ФЗ создал юридическую схему бизнеса, выгодную, прежде всего, для оператора финансовой платформы - организациипосредника. Предлагаются изменения и дополнения в Федеральный закон от 20.07.2020 № 211-Ф3. Обоснована целесообразность заимствования и интегрирования в единый федеральный закон «О совершении потребителями инвестиционных сделок в информационно-телекоммуникационной сети Интернет» всех жизнеспособных законодательных положений, разработанных в Федеральном законе от 20.07.2020 № 211-Ф3. В данном документе предлагается также закрепить комплекс правил регулирования дистанционно-цифровых сделок инвестирования в традиционные финансовые активы, в ценные бумаги, в цифровые финансовые активы, в производные финансовые активы, совершаемых розничными частными инвесторами (физическими лицами) в информационно-телекоммуникационной сети Интернет.
\end{abstract}

Ключевые слова: инвестиционные сделки, инвестиционные услуги, инвестор (потребитель финансовых услуг), информационно-телекоммуникационная сеть Интернет, дистанционно-цифровые сделки, финансовые активы, финансовая платформа, блокчейн технологии.

Цитирование. Матыцин Д. Е. Законодательные новеллы регулирования инвестиционных сделок, совершаемых с использованием финансовой платформы: оценка эффективности // Legal Concept $=$ Правовая парадигма. -2021. - Т. 20, № 3. - C. 125-137. - DOI: https://doi.org/10.15688/lc.jvolsu.2021.3.19 


\section{Введение}

Федеральный закон от 20 июля 2020 г. № 211-Ф3 «О совершении финансовых сделок с использованием финансовой платформы» вступил в силу в 2020 г. и регулирует деятельность особых юридических лиц - операторов, которые оказывают частным лицам инвестиционные услуги [20]. Эти услуги предусматривают создание условий для граждан по совершению в Интернете сделок двух видов: частный инвестор - финансовая организация; частный инвестор - эмитент. Несомненно, указанные сделки в полной мере относимы к дистанционно-цифровым инвестиционным сделкам.

В отличие от правоведов экономисты довольно активно разрабатывают вопросы формирования новых подходов к дистанционному предоставлению финансовых услуг широкому кругу потребителей $[4$, с. $41-51 ; 6$, c. $134-142 ; 7 ; 9$, с. $280-292 ; 12$, c. $91-101 ; 14$, c. $86-98 ; 17$, c. $59-69 ; 18 ; 26$, c. $91-100 ; 27 ; 28$; $29 ; 30]$. Полагаем, что цивилистическая доктрина в части исследования тематики инвестиционных сделок, совершаемых с использованием финансовой платформы, пока только формируется, при этом ученые юристы отрасли финансового права немного впереди [2, c. $149-152 ; 11$, с. $228-234 ; 13$, c. $45-51 ; 15$, c. $27-31 ; 20$, c. $28-33]$.

Оператор финансовой платформы содействует частным инвесторам (потребителям финансовых услуг) в совершении сделок, вопервых, с финансовыми организациями, во-вторых, с эмитентами. Зададимся вопросом, как это облегчало, ускоряло, упрощало совершение частным инвестором таких сделок, если бы он не обращался на данную посредническую площадку? Ответы получим в итоге детального анализа правового регулирования, закрепленного в Федеральном законе от 20 июля 2020 г. № 211-Ф3 «О совершении финансовых сделок с использованием финансовой платформы» (Федеральный закон от 20.07.2020 № 211-Ф3).

\section{Финансовая платформа}

\section{как новая инвестиционная площадка}

Исходя из названия Федерального закона от 20.07.2020 № 211-Ф3, можно предположить, что Законодателем реализован порядок применения оператором финансовой платформы особой информационной технологии, суть которой - веб-сайт с передовыми сервисами для несложного совершения частными инвесторами дистанционно-цифровых сделок. Мы полностью поддерживаем решение Законодателя о том, что для оказания услуг частным инвесторам у оператора финансовой платформы должны быть во владении основной и резервный комплексы программно-аппаратных средств, которые обеспечивают непрерывную работу платформы (веб-сайта), сохранность данных и их резервное копирование. Причем сами комплексы программно-аппаратных средств, согласно закону, должны быть расположены на территории Российской Федерации.

Банк России непосредственно причастен к легитимации юридического лица в статусе оператора финансовой платформы. Согласно ст. 11 Федерального закона от 20 июля 2020 г. № 211-Ф3 заявитель подает от семи до десяти разновидностей документов, Банк России в срок до 30 дней их рассматривает, затем включает (либо отказывает заявителю включить) сведения о нем в Реестр операторов финансовых платформ [26]. По нашему мнению, это та же процедура лицензирования, только более экономичная, потому что реестр - это всего лишь таблица на веб-сайте Банка России, не нужно изготавливать бланк лицензии, оформлять ее, подписывать, выдавать документ юридическому лицу. Заметим, что в семи определенных ситуациях Банк России вправе принять решение об исключении сведений об операторе финансовой платформы из указанного реестра. Добровольно оператор финансовой платформы вправе подать Банку России заявление о своем исключении из реестра в связи прекращением данного бизнеса только при условии отсутствия обязательств перед участниками финансовой платформы по договору об оказании услуг оператора финансовой платформы.

Для деятельности оператора финансовой платформы характерна полная информационная прозрачность. Тринадцать позиций данных об операторе должны быть раскрыты на его веб-сайте и находиться в свободном доступе. Так, например, установлена обязанность представить на веб-сайте Правила финансовой 
платформы, зарегистрированные в Банке России; указать на веб-сайте размер вознаграждения оператора (порядок его определения), указать порядок уплаты услугополучателем такого вознаграждения; раскрыть на веб-сайте реквизиты специального счета (счетов) оператора финансовой платформы. Наряду с этим, на веб-сайте должны быть раскрыты все лица, которые ведут учет прав на ценные бумаги (права на которые потребители финансовых услуг получают при совершении финансовых сделок). Должен быть представлен перечень лиц, которых оператор финансовой платформы привлек с целью размещения данных о совершаемых на платформе финансовых сделках и раскрыт состав банков, которые по поручению оператора платформы осуществляют идентификацию потребителей финансовых услуг. Осуществляют идентификацию и представителей этих потребителей, а также выгодоприобретателей, бенефициарных владельцев при заключении с такими лицами договора об оказании услуг оператора финансовой платформы при их личном присутствии. Помимо этого, раскрываются реквизиты веб-сайтов, фирменные наименования и места нахождения финансовых организаций и то же самое - эмитентов, являющихся участниками финансовой платформы (ст. 13 Федерального закона от 20 июля 2020 г. № 211-Ф3).

Кроме того, в рамках ст. 12 Федерального закона от 20 июля 2020 г. № 211-ФЗ Законодатель большое внимание обращает на порядок работы с данными, которые получает оператор финансовой платформы при оказании услуг. Требования к защите информации и по операционной надежности, установленные в Федеральных законах от 10 июля 2002 г. № 86-Ф3 «О Центральном банке Российской Федерации (Банке России)» [23] (защита информации, информационная надежность), от 7 августа 2001 г. № 115-Ф3 «О противодействии легализации (отмыванию) доходов, полученных преступным путем, и финансированию терроризма» [22] (аутентификация участника финансовой платформы) оператором должны неукоснительно соблюдаться. Законодателем отдельно закреплено, что оператор непрерывно проводит мероприятия, предусматривающие выявление попыток совер- шения сделок на финансовой платформе без волеизъявления участников финансовой платформы, оператор обязан противодействовать совершению таких сделок. Если такие действия имеют место, о них оператор обязан уведомлять Банк России, который формирует специальную базу данных о таких случаях.

По нашему мнению, юридическим регламентационным базисом предпринимательской деятельности оператора финансовой платформы являются Правила финансовой платформы. Этот документ проходит регистрацию в Банке России одновременно с приобретением юридическим лицом - заявителем правового статуса оператора финансовой платформы, возникающий, как отмечено выше, с момента включения оператора в Реестр операторов финансовых платформ. Если у оператора в процессе ведения деятельности возникает необходимость внести в Правила изменения и (или) дополнения, в Банк России представляются Правила финансовой платформы в новой редакции. Представляюется заявление о регистрации изменений (этот электронный документ создается с использованием компьютерной программы с веб-сайта Банка России), копия решения оператора об утверждении изменений в Правила финансовой платформы, документ, в котором выделены вносимые в Правила финансовой платформы изменения, а также объясняются причины внесения изменений (ст. 16 Федерального закона от 20 июля 2020 г. № 211-Ф3). Как видим, Правила финансовой платформы суть Устав по ведению данного дистанционноцифрового бизнеса в инвестиционной сфере.

Так, в ст. 4 Федерального закона от 20 июля 2020 г. № 211-ФЗ Законодатель установил шестнадцать развернутых позиций, которые подробнейшим образом регламентируют содержание Правил финансовой платформы. Первое: требования, которым должны соответствовать участники данной финансовой платформы (правоспособность юридических лиц, дееспособность потребителей финансовых услуг). Второе: варианты сделок, совершаемых по Правилам, установленным на данной платформе. Третье: положения договора с условиями оказания услуг оператором финансовой платформы. Логично, что указанный договор является договором присоединения, 
включающим права и обязанности оператора финансовой платформы, присоединившихся к этому договору потребителей финансовых услуг, финансовых организаций или эмитентов. Кроме того, этот договор регламентирует порядок взаимодействия между оператором финансовой платформы и указанными субъектами при заключении и исполнении финансовых сделок. Опустим позиции с четвертой по седьмую. Восьмое: регламентация указаний через финансовую платформу потребителя финансовых услуг оператору финансовой платформы. Данные указания на определенных условиях принимаются к исполнению, после чего исполняются, затем в определенный срок об их исполнении оператор финансовой платформы сообщает потребителю финансовых услуг. Девятое: в составе указаний потребителя финансовых услуг для оператора регламентируется срок, в течение которого оператор обязан дать от своего лица распоряжение в кредитную организацию о совершении операций по специальному счету оператора на основании указания, полученного от потребителя финансовых услуг. Если не установлен конкретный срок (дата), оператор обязан дать распоряжение о списании денежной суммы со специального счета в течение одного рабочего дня с момента получения оператором указания от потребителя финансовых услуг.

Ключевым юридическим инструментом, посредством которого организуется взаимодействие всех субъектов финансовых дистанционно-цифровых сделок, является договор об оказании услуг оператора финансовой платформы. Условия договора закреплены и представлены в Правилах финансовой платформы, участники финансовой платформы становятся стороной договора, присоединяясь к нему в ходе электронно-дистанционного взаимодействия. В рамках этого договора об оказании услуг оператора финансовой платформы услугодатель (оператор) обязуется по действующим Правилам финансовой платформы оказывать специфические услуги. Во-первых, содержание его услуг - предоставить на платформе информацию участникам финансовой платформы для совершения дистанционноцифровой финансовой сделки. Во-вторых, оператор в рамках этого договора может обеспечивать информационное взаимодействие участников финансовой платформы непосредственно для совершения финансовых сделок (ст. 3 Федерального закона от 20 июля 2020 г. № 211-Ф3).

Согласно ст. 6 Федерального закона от 20 июля 2020 г. № 211-Ф3 принципиально важным элементом предпринимательского строения финансовой платформы и услуг самого оператора является специальный счет, который оператор финансовой платформы императивно обязан открыть в системно значимой кредитной организации на территории Российской Федерации, заключив договор специального счета. В этот банк оператор ежедневно в рабочие дни предоставляет за предыдущий рабочий день сведения об общем денежном остатке на этом специальном счете и о персональных остатках денежных средств каждого потребителя финансовых услуг внутри общего денежного остатка. Следует уточнить, что указанная обязанность оператора финансовой платформы может быть установлена указанным выше договором специального счета и сторонами договора специального счета для банка, в котором функционирует данный специальный счет. По нашему мнению, специальный счет представляет собой электронно-дистанционный транзитный инструмент разграничения прав собственности на денежные средства оператора финансовой платформы и потребителей финансовых услуг.

Восемь разновидностей операций могут проводиться по специальному счету оператора финансовой платформы. Прежде всего, зачисление денежных сумм в пользу частного инвестора, например, со счета его банковского вклада по окончании срока вклада и в его пользу могут быть зачислены согласно условиям финансовой сделки данного частного инвестора с финансовой организацией или с эмитентом в качестве исполнения от указанной стороны, обязанной по сделке или как доход (иная выплата) по тем или иным ценным бумагам. Допускается также зачисление денег в пользу потребителя финансовых услуг в виде страховой выплаты по Федеральному закону от 23 декабря 2003 г. № 177-Ф3 «О страховании вкладов в банках Российской Федерации» [21]. Закономерно, что в соответствующих случаях по специальному счету будут осуществляться расходы - списания 
денежных сумм по указаниям частного инвестора по конкретным финансовым сделкам, а также в качестве денежного вознаграждения оператору финансовой платформы по договору. Следует уточнить, что списание денежных сумм будет также осуществлено со специального счета (из соответствующего остатка определенного частного инвестора по его обязательствам), если в банк будет представлено решение суда, имеются и иные, предусмотренные федеральными законами случаи.

Информация о движении принадлежащих потребителю финансовых услуг денежных средств по специальному счету доводится до него оператором бесплатно в порядке, предусмотренном Правилами финансовой платформы. В ч. 10 ст. 6 Федерального закона от 20 июля 2020 г. № 211-Ф3 Законодатель закрепил норму о том, что срок направления частному инвестору информации о движении денежных средств не может превышать один рабочий день со дня их зачисления (списания).

Следует отметить, что частный инвестор вправе выбрать способ возврата со специального счета принадлежащих ему денежных средств, закрепив этот способ в договоре об оказании услуг оператора финансовой платформы. Несомненно, данный договорный способ возврата денег потребителю финансовых услуг может быть заменен сторонами на другой способ при необходимости. Очевидно, что частный инвестор должен включить в договор об оказании услуг оператора финансовой платформы со своей стороны реквизиты своего банковского счета физического лица. Уточним, что в зависимости от полноты правоспособности оператора финансовой платформы (например, исключение из Реестра операторов финансовых платформ) договор специального счета может прекратиться. Здесь, во-первых, возникает вопрос о судьбе денежных средств, которые принадлежат частному инвестору. Законодатель решил, что остаток этих денег выдается кредитной организацией потребителю финансовых услуг наличными либо по указанию последнего зачисляется на любой его банковский счет физического лица безналичными денежными средствами. Во-вторых, показанная гипотетическая ситуация с исключением оператора из Реестра операторов финансовых платформ ярко высвечивает сугубо посредническую функцию оператора финансовой платформы между частным инвестором и кредитной организацией, в которой имеется специальный счет.

В ст. 7 Федерального закона от 20 июля 2020 г. № 211-Ф3 находится упоминание о регистраторе финансовых транзакций, которое мы встречали в ст. 2. Казалось бы, что это некое новое субъектное явление в инвестиционном обороте, но на самом деле Законодателем так экзотично назван репозитарий (сам центральный депозитарий либо его 100 \%-ное дочернее общество), который ведет учет финансовых сделок. В словаре банковских терминов раскрывается термин «трансакция» слово, производное от английского transaction - «дело, сделка, соглашение». По сути, имеется в виду операция с денежными средствами: перевод, вывод или зачисление денег на банковский счет [10]. К сожалению, Законодатель, по нашему мнению - для красного словца, создал в федеральном законе новый термин для юридического лица специальной правоспособности, под которым понимается всего лишь регистратор операций с денежными средствами.

Репозитарий, ведущий учет финансовых сделок, действует в рамках Правил осуществления репозитарной деятельности. Оператор финансовой платформы обязан досконально знать и соблюдать эти Правила (порядок, состав, форма, сроки предоставления сведений), предоставлять репозитарию (регистратору финансовых транзакций) полную и, что особенно важно - достоверную, следующую информацию:

1. О размещенных с использованием финансовой платформы банковских вкладах и об операциях с денежными средствами по ним (обязанность оператора).

2. О совершении иных финансовых сделок и об операциях по ним с использованием финансовой платформы (обязанность оператора).

3. Когда это предусмотрено Правилами осуществления репозитарной деятельности может предоставлять регистратору финансовых транзакций иную информацию по таким сделкам (право оператора).

Также в ст. 7 Федерального закона от 20 июля 2020 г. № 211-Ф3 регламентирован 
правовой режим предоставления информации, которую репозитарий (регистратор финансовых транзакций) доводит до указанных в законе субъектов. Во-первых, это сам клиент репозитария; во-вторых, суды (судьи); в-третьих, органы предварительного следствия; в-четвертых, Государственная корпорация «Агентство по страхованию вкладов»; в-пятых, нотариус, ведущий наследственное дело; в-шестых, иные лица в соответствии с федеральными законами. Положительно, что Законодатель допускает доведение информации до самого потребителя финансовых услуг через интернет-портал «Госуслуги». При этом способ доведения информации до частного инвестора выбирается репозитарием (регистратором финансовых транзакций) из его же Правил осуществления репозитарной деятельности. Кроме того, репозитарию дозволяется использовать единую систему идентификации и аутентификации, а также межведомственного электронного взаимодействия. Указанному субъекту разрешается получить целый комплекс касающихся частного инвестора персональных данных: номер оператора подвижной радиотелефонной связи и адреса электронной почты потребителя финансовых услуг, его СНИЛС в ПФР и др.

Ряд особенностей Законодатель выделяет, регламентируя сам процесс совершения финансовых сделок в ст. 5 Федерального закона от 20.07.2020 № 211-Ф3:

1. Только договор страхования именно как договор в пользу третьего лица (при необходимости) можно заключить с использованием финансовой платформы. Другие договоры в пользу третьего лица на финансовой платформе не могут заключаться.

2. При исполнении денежных обязательств участниками финансовой платформы не допускается зачисление денежных средств, которые принадлежат (причитаются) частным инвесторам, на банковские счета, где размещаются собственные денежные средства оператора финансовой платформы.

3. Денежные средства потребителя финансовых услуг через оператора финансовой платформы могут зачисляться либо напрямую на банковский счет финансовой организации (на банковский счет эмитента), с которой (которым) потребителем заключена финансовая сделка, либо на специальный счет, открытый в банке оператору финансовой платформы, либо на банковский счет самого частного инвестора как физического лица.

4. Возможна ситуация, при которой потребитель финансовых услуг заключит договор банковского вклада через финансовую платформу, затем этот договор изменит или вообще прекратит, но без использования финансовой платформы, что вполне законно и допустимо. В такой ситуации у банка - стороны по такому договору банковского вклада - возникает обязанность сообщить об этом факте оператору финансовой платформы, причем сообщить незамедлительно, при этом подобная ситуация должна регламентироваться Правилами финансовой платформы.

5. Трансферт частному инвестору ценных бумаг во исполнение обязательств по финансовой сделке, совершенной с использованием финансовой платформы, завершается зачислением этих ценных бумаг только на лицевой счет (счет депо) данного частного инвестора в депозитарии.

6. Выданное через финансовую платформу распоряжение частного инвестора о списании ценных бумаг с его лицевого счета (со счета депо) исполняется только путем зачисления этих ценных бумаг на иные лицевые счета или счета депо другого частного инвестора (в том числе через номинального держателя ценных бумаг), либо путем их передачи (возврата) финансовой организации или эмитенту в целях исполнения обязательств по финансовой сделке.

7. Стороны финансовых сделок с ценными бумагами отдельно регламентируются Законодателем. Субъекты, с одной стороны, только потребитель финансовых услуг, с другой - лица, обязанные по таким ценным бумагам. В том числе эмитенты ценных бумаг в отношении ценных бумаг, выпущенных ими самими, а также лица, действующие по поручению эмитентов. В том числе финансовые организации, имеющие лицензию на осуществление дилерской деятельности. Дилер совершает финансовые сделки путем объявления цен: а) продажи определенных ценных бумаг с обязательством продажи таких ценных бумаг по объявленным ценам; б) покупки ценных бумаг такого эмитента с обязательством 
покупки этих ценных бумаг по объявленным ценам. Следует уточнить, что по финансовым сделкам с ценными бумагами, допущенными к организованным торгам, покупателями таких бумаг могут выступать только частные инвесторы - потребители финансовых услуг.

8. Обязанное по ценным бумагам лицо может выплатить по ним деньги (если бумаги принадлежат частному инвестору) на специальный счет оператора финансовой платформы. Такую же выплату может осуществить депозитарий. Это, очевидно, можно реализовать при условии, что реквизиты специального счета переданы потребителем финансовых услуг регистратору или депозитарию (который учитывает права потребителя финансовых услуг на такие ценные бумаги), а также при условии присоединения регистратора или депозитария к договору об оказании услуг оператора финансовой платформы. Сам регистратор или депозитарий, совмещая бизнесы, может действовать еще и как оператор финансовой платформы.

9. Исходя из требований к лицам, которые могут являться стороной сделок, или к лицам, в пользу и (или) за счет которых могут совершаться сделки с использованием финансовой платформы, должны соблюдаться особые ограничения, установленные Федеральным законом от 22 апреля 1996 г. № 39-Ф3 «О рынке ценных бумаг» [24]. Во-первых, ограничения на заключение сделок с ценными бумагами. Во-вторых, ограничения на заключение договоров, являющихся производными финансовыми инструментами. В-третьих, ограничения на заключение иных сделок на рынке ценных бумаг. В-четвертых, имеется общее ограничение: если требования, связанные с участием в определенных сделках, не подлежат судебной защите, то такие сделки недопустимо совершать с использованием финансовой платформы.

\section{Результаты}

По истечении года послевступления в силу Федерального закона от 20.07.2020 № 211-Ф3 Реестр операторов финансовых платформ выглядел более чем скромно. На веб-сайте Банка России в указанном реестре мы видим всего лишь 3 организации: Публичное акционер- ное общество «Московская Биржа ММВБ-РТС»; Акционерное общество ВТБ Регистратор; Акционерное общество «Специализированный депозитарий «ИНФИНИТУМ» [3]. Как было отмечено выше, фактически все 3 организации стали операторами финансовых платформ на условиях совмещения бизнесов.

К сожалению, хотя и прошел год после вступления в силу Федерального закона от 20.07.2020 № 211-Ф3, на веб-сайте финансовой платформы Мосбиржи мы видим довольно слабый ассортимент предложений для инвестирования [8]: 9 вкладов в различных коммерческих банках, а также единственное предложение по страхованию - оформление электронного полиса ОСАГО. Следует подтвердить, что в Правилах финансовой платформы Публичного акционерного общества «Московская Биржа ММВБ-РТС» (Зарегистрированы Банком России 24.12.2020 (Уведомление Банка России о регистрации документа Публичного акционерного общества «Московская Биржа ММВБ-РТС» от 24.12.2020 № 14-6-10/10650)) в разделе 6 «Финансовые сделки», в пункте 6.3 действительно закреплено такое правило: «6.3 Оператор платформы обеспечивает возможность совершения следующих Финансовых сделок: 1) договор банковского вклада (депозита); 2) договор обязательного страхования» [8].

На веб-сайте финансовой платформы АО ВТБ Регистратор [5] мы находим только 1 вариант инвестирования - предлагаются облигации субъекта Российской Федерации - Томской области (RU25068TMSO; RU25071TMSO). Однако имеется ли возможность их продать, получить стоимость погашения в конце срока облигаций, не указано. На веб-сайте $\mathrm{AO}$ «Специализированный депозитарий «ИНФИНИТУМ» представлено 44 варианта инвестирования в различные паевые инвестиционные фонды [25]. При этом фактически купить можно паи только 20 паевых инвестиционных фондов, не указано, есть ли возможность продать имеющиеся паи обратно через эту же платформу. Также на веб-сайте $\mathrm{AO}$ «Специализированный депозитарий «ИНФИНИТУМ» указано довольно странное изречение, что Финансовая платформа - это цифровая перезагрузка ПИФ [1].

По нашему мнению, такая фатальная неактивность хозяйствующих субъектов под- 
тверждает следующую нашу позицию. Федеральный закон от 20.07.2020 № 211-Ф3 перегружен громоздкими конструкциями, содержит излишества по количеству участвующих в регулируемых отношениях субъектов, а также имеет дисбаланс по объему сложных обязанностей, который не покрывается экономическими интересами их исполнителей. Прежде всего, тщательный анализ приводит к пониманию того, что никакой финансовой платформы, которая давала бы частному инвестору (потребителю финансовых услуг) прибыль от инвестирования, вообще-то не существует. Фактически существует только вебсайт - визитная карточка организации-посредника. Поразительно, но сам Законодатель, раскрывая самое первое из основных понятий, используемых в законе, указывает, что «финансовая платформа - информационная система, которая обеспечивает взаимодействие финансовых организаций или эмитентов с потребителями финансовых услуг посредством информационно-телекоммуникационной сети "Интернет"» (ст. 2 Федерального закона от 20.07.2020 № 211-Ф3).

Можно сформулировать это следующим образом: имеется веб-сайт инвестиционного посредника (оператора), способного помочь розничному частному инвестору заключить, например, договор банковского вклада, страхования автогражданской ответственности или договор покупки облигаций. Однако «на платформе» этому частному инвестору предстоит: 1) заключить договор с этим оператором; 2) зачислить деньги на специальный счет этого оператора; 3) дать указание, в какой банк, на какой вклад деньги разместить; 4) заплатить оператору за услуги. Из представленных согласно закону 4 шагов - 3 шага нерациональные и совершенно бессмысленные. С ценными бумагами ситуация складывается еще более тяжелая. Розничному частному инвестору, который не идет «на финансовую платформу», необходимо открыть брокерский счет, зачислить на него сумму, затем можно давать брокеру поручение о приобретении тех или иных ценных бумаг, заключить договор с депозитарием. Но согласно Федеральному закону от 20.07.2020 № 211-Ф3 получается, что частный инвестор должен: 1) заключить договор с этим оператором; 2) зачислить деньги на спе- циальный счет этого оператора; 3) заключить договор на брокерское обслуживание; 4) дать оператору указание о транзите денег на брокерский счет; 5) заплатить оператору за услуги; 6) дать брокеру поручение о приобретении ценных бумаг; 7) заплатить брокеру за услуги; 8) вступить в договорные отношения с регистратором финансовых транзакций.

Здесь сразу возникает вопрос, а что у конкретного банка, в который, пройдя транзитом через «финансовую платформу», будет помещен денежный вклад розничного частного инвестора, веб-сайт больше не работает? Разве розничный частный инвестор, который может отыскать в Интернете веб-сайт загадочного в своей новизне субъекта - оператора финансовой платформы, почему-то вдруг не смог отыскать веб-сайт банка и заключить с ним договор банковского вклада? Каким же образом тогда в российских коммерческих банках в начале 2021 г. накоплены более 20 трлн руб. вкладов населения? Те же аргументы можно приводить в отношении сделок розничного частного инвестора с ценными бумагами.

В «Толковом словаре В.И. Даля» платформа - это помост, настилка, пол, ток, ладонь, для установки чего-либо, напр. пушки; помост перед караульней [16]. Финансы мы понимаем как работающие деньги и отношения по поводу рационального осуществления денежных потоков. Однако, глубоко вникнув в положения Федерального закона от 20.07.2020 № 211-Ф3, видим, что финансовая площадка не позволяет рационально выстроить денежные потоки. Невозможно розничному частному инвестору (потребителю финансовых услуг) достичь самой главной цели инвестирования - прибыли. Поскольку инвестирование с обращением ко вновь созданному Законодателем инвестиционному посреднику (оператору финансовой платформы) не происходит легче, быстрее, проще, а главное, такое обращение влечет затраты, которых можно избежать и которых до вступления в силу Федерального закона от 20.07.2020 № 211-Ф3 у частного инвестора вообще не было.

\section{Выводы}

Таким образом, деятельность по учету данных о финансовых сделках, которую 
репозитарий (регистратор финансовых транзакций) согласно Федеральному закону от 20.07.2020 № 211-Ф3 должен осуществлять, весьма громоздкая, сложная и затратная, подвержена рискам ненадлежащего исполнения и ненадлежащего сохранения персональных данных потребителей финансовых услуг. Предлагаем для учета сведений о финансовых сделках с использованием финансовой платформы применять депозитарно-регистрационную платформу, функционирующую в качестве специального электронного сервиса на веб-сайте Банка России. Фиксацию фактов совершаемых финансовых сделок следует осуществлять в системе полисубъектного юрисдикционного блокчейна. В схему полисубъектного блокчейна должны быть объединены 6 субъектов, действующих на территории Российской Федерации: частный инвестор; оператор финансовой платформы; Минцифры России (веб-сайт «Госуслуги» с личным кабинетом инвестора); Федеральная налоговая служба (веб-сайт ФНС с личным кабинетом юридического лица - контрагента оператора финансовой платформы); Банк России (веб-сайт Банка России с депозитарно-регистрационной платформой для данных о финансовых сделках); Верховный Суд Российской Федерации (веб-сайт Суда со специальным сервисом хранения доказательств в электронной форме).

Это позволит каждому участнику блокчейна одновременно получать полную и достоверную информацию по каждому этапу совершаемой финансовой сделки в режиме онлайн; исключить нерациональную и бессмысленную передачу данных, касающихся финансовых сделок и их участников; вывести лишнего участника (регистратора финансовых транзакций) из межсубъектного взаимодействия, снизить риск ненадлежащего сохранения персональных данных потребителей финансовых услуг. В этой части Федеральный закон от 20.07.2020 № 211-Ф3 требует предложенных изменений и дополнений.

Следует сделать вывод, что для юридических лиц, участвующих в финансовых сделках, совершаемых с использованием финансовой платформы, бизнес происходит с положительными финансовыми результатами. Получается, что Законодатель в Федеральном законе от 20.07.2020 № 211-Ф3 создал юридическую схему бизнеса, выгодную, прежде всего, для оператора финансовой платформы - организации-посредника. От функционирования финансовой платформы банки получают вклады, страховщики получают страховые премии, брокеры за комиссионные оказывают брокерские услуги, репозитарий оказывает депозитарные услуги, сам оператор финансовой платформы получает прибыль, оказывая услуги, предусмотренные законом. Но все указанные прибыли одновременно являются затратами, которые оплачивает розничный частный инвестор (потребитель финансовых услуг). Федеральный закон от 20.07.2020 № 211-Ф3 перегружен громоздкими конструкциями, содержит излишества по количеству участвующих в регулируемых отношениях субъектов, а также имеет дисбаланс по объему сложных обязанностей, который не покрывается удовлетворением экономических интересов исполнителей этих обязанностей.

Необходимо все жизнеспособные законодательные положения, разработанные в Федеральном законе от 20.07.2020 № 211-Ф3, заимствовать и интегрировать в единый федеральный закон «О совершении потребителями инвестиционных сделок в информационно-телекоммуникационной сети “Интернет"». В этом федеральном законе следует закрепить комплекс правил регулирования дистанционно-цифровых сделок инвестирования в традиционные финансовые активы, в ценные бумаги, в цифровые финансовые активы, в производные финансовые активы, совершаемых розничными частными инвесторами (физическими лицами) в информационно-телекоммуникационной сети Интернет.

\section{ПРИМЕЧАНИЕ}

${ }^{1}$ Исследование выполнено при финансовой поддержке РНФ в рамках научного проекта № 2018-00314 «Трансформация общественных отношений в условиях индустрии 4.0: юридическая превенция».

The research was carried out with the financial support of the Russian National Research Foundation within the framework of Scientific Project No. 20-1800314 "Transformation of public relations in the conditions of Industry 4.0: legal prevention". 


\section{СПИСОК ЛИТЕРАТУРЫ}

1. АО «Специализированный депозитарий «ИНФИНИТУМ». Официальный сайт. - Электрон. текстовые дан. - Режим доступа: https://specdep.ru/platform/ (дата обращения: 14.05.2021). - Загл. с экрана.

2. Арзуманова, Л. Л. Новеллы законодательства по финансовым сделкам / Л. Л. Арзуманова // Вестник Университета имени О.Е. Кутафина (МГЮА). - 2018. - №9 (49). - С. 149-152.

3. Банк России. Официальный сайт. - Электрон. текстовые дан. - Режим доступа: http:// www.cbr.ru/registries/?cf.date.time=Any\&cf.search/ (дата обращения: 14.05.2021). - Загл. с экрана.

4. Бауэр, В. П. Цифровые платформы как инструмент трансформации мировой и российской экономики в 2021-2023 годах / В. П. Бауэр, В. В. Еремин, В. В. Смирнов // Экономика. Налоги. Право. 2021. - № 14 (1). - C. 41- 51. - DOI : 10.26794/1999849X2021-14-1-41-51.

5. ВТБ Регистратор. Официальный сайт. Электрон. текстовые дан. - Режим доступа: https:// pos.vtbreg.ru/marketplace/marketplace/market.html (дата обращения: 14.05.2021). - Загл. с экрана.

6. Комаров, А. В. Необанкинг как направление развития современных финансовых технологий / А. В. Комаров, В. М. Мартюкова // Вестник университета. - 2020. - № 3. - С. 134-142.

7. Месропян, В. Р. Цифровые платформы-новая рыночная власть / В. Р. Месропян. - Электрон. текстовые дан. - Режим доступа: https:// www.econ.msu.ru/science/News.20180417134253_6961/ (дата обращения: 08.05.2021). - Загл. с экрана.

8. Московская Биржа. Официальный сайт. Электрон. текстовые дан. - Режим доступа: https:// finuslugi.ru/vklady/katalog/vse-vklady (дата обращения: 14.05.2021). - Загл. с экрана.

9. Никонец, О. Е. Дистанционное банковское обслуживание как элемент экосистемы современного банка / О. Е. Никонец, К. А. Попова // Вестник Волжского университета имени В.Н. Татищева. 2020. - T. 2. - № 1. - С. 280-292.

10. ООО ИА «Банки.ру». Официальный сайт. Словарь банковских терминов. - Электрон. текстовые дан. - Режим доступа: https:/www.banki.ru/ wikibank/transaktsiya/ (дата обращения: 14.05.2021).

11. Пастушенко, Е. Н. Новеллы правового регулирования развития защиты прав потребителей финансовых услуг как функции Центрального банка Российской Федерации в условиях цифровой экономики / Е. Н. Пастушенко, Л. Н. Земцова // Вестник Саратовской государственной юридической академии. - 2020 - № 5 (136). - С. 228-234.

12. Петрова, Л. А. Цифровизация банковской системы: цифровая трансформация среды и бизнес-процессов / Л. А. Петрова, Т. Е. Кузнецова
// Финансовый журнал. - 2020. - Т. 12. - № 3. C. 91-101.-DOI: 10.31107/2075-1990-2020-3-91-101.

13. Раздорожный, К. Б. Банк России как регулятор на рынке финансовых технологий / К. Б. Раздорожный // Актуальные проблемы российского права. -2021. - Т. 16, № 3. -C. 45-51. -DOI: 10.17803/ 1994-1471.2021.124.3.045-051.

14. Самиев, П. А. Экосистемы и маркетплейсы: обзор рынка финансовых услуг / П. А. Самиев, В. Р. Закирова, Д. В. Швандар // Финансовый журнал. - 2020. - Т. 12. - № 5. - С. 86-98. - DOI: 10.31107/ 2075-1990-2020-5-86-98.

15. Ситник, А. А. Финансовые технологии: понятие и виды / А. А. Ситник // Актуальные проблемы российского права. - 2019. - № 6. - С. 27-31.

16. Словари онлайн. Официальный сайт. Толковый словарь Даля онлайн. - Электрон. текстовые дан. - Режим доступа: http://slovardalja.net/ word.php? wordid=26144 (дата обращения: 14.05.2021). - Загл. с экрана.

17. Смирнов, Е. Н. Императивы управления глобальными цифровыми платформами / Е. Н. Смирнов, С.А. Лукьянов // Управленец. - 2020. T. 11, № 4. - C. 59-69. - DOI: 10.29141/2218-50032020-11-4-5.

18. Тропская, С. С. Финансовый рынок в условиях развития цифровой экономики (финансовоправовой аспект) / С. С. Тропская // Финансовое право. - 2018. - № 8. - С. 28-33.

19. Федеральный закон от 10 июля 2002 г. № 86-Ф3 «О Центральном банке Российской Федерации (Банке России)» // Российская газета. - 2002. - Июль (№ 127).

20. Федеральный закон от 20 июля 2020 г. № 211-Ф3 «О совершении финансовых сделок с использованием финансовой платформы» // Российская газета. - 2020. - Июль (№ 162).

21. Федеральный закон от 22 апреля 1996 г. № 39-Ф3 «О рынке ценных бумаг» // Российская газета. - 1996. - Апр. (№ 79).

22. Федеральный закон от 23 декабря 2003 г. № 177-Ф3 «О страховании вкладов в банках Российской Федерации» // Российская газета. - 2003. - Дек. (№ 261).

23. Федеральный закон от 7 августа 2001 г. № 115-Ф3 «О противодействии легализации (отмыванию) доходов, полученных преступным путем, и финансированию терроризма» // Российская газета. - 2001. - Авг. (№ 151).

24. Финансовая платформа реализована Группой компаний «ИНФИНИТУМ». Официальный сайт. - Электрон. текстовые дан. - Режим доступа: https://platform.finance/ (дата обращения: 14.05.2021). Загл. с экрана.

25. Финансовое право в условиях развития цифровой экономики : монография / К. Т. Анисина [и др.] ; под ред. И. А. Цинделиани. - М. : Проспект, 2019. 
26. Формирование экосистем банков в условиях цифровизации банковского пространства / Н. И. Быканова, Ю. А. Соловей [и др.] // Экономика. Информатика. - 2020. - Т. 47, № 1. - С. 91-100.

27. Accenture. Five Ways to Win with Digital Platforms. - Electronic text data. - Mode of access: https://www.accenture.com/nl-en/insight-g20-yeadigital-platforms\#blockhero (date of access: 08.05.2021). - Title from screen.

28. Daum, T. Understanding Digital Capitalism / T. Daum. - Electronic text data. - Mode of access: http://dasfilter.com/gesellschaft/understandingdigital-capitalism-what-time-are-we-living-in-anintroduction. - Title from screen.

29. Schiller, D. Digital capitalism stagnation and contention? / D. Schiller. - Electronic text data. - Mode of access: https://www.opendemocracy.net/ digitaliberties/dan-schiller/digital-capitalismstagnation-and-contention (date of access: 08.05.2021). - Title from screen.

30. Van Alstyne, M. Pipelines, Platforms, and the New Rules of Strategy / M. Van Alstyne, G. Parker, S. P. Choudary // Harvard Business Review. - 2016. - April. - Electronic text data. Mode of access: http://ide.mit.edu/sites/default/ files/publications/Pipelines $\% 2 \mathrm{C} \% 20 \mathrm{Platforms}$ $\% 2 \mathrm{C} \% 20$ and $\% 20$ the $\% 20 \mathrm{New} \% 20$ Rules $\% 20$ of $\%$ 20Strategy.pdf.pdf (date of access: 08.05.2021). Title from screen.

\section{REFERENCES}

1. AO «Specializirovannyj depozitarij «INFINITUM». Oficial'nyj sajt. URL: https:// specdep.ru/platform/ (accessed 14 May 2021).

2. Arzumanova L.L. Novelly zakonodatel'stva po finansovym sdelkam [Novelties of Legislation on Financial Transactions]. Vestnik Universiteta imeni O.E. Kutafina (MGJuA) [Bulletin of the O. E. Kutafin University (MSLA)], 2018, no. 9(49), pp. 149-152.

3. Bank Rossii. Oficial'nyj sajt. URL: http:// www.cbr.ru/registries/?cf.date.time=Any\&cf.search/ (accessed 14 May 2021).

4. Baujer V.P., Erjomin V.V., Smirnov V. V. Cifrovye platformy kak instrument transformacii mirovoj i rossijskoj jekonomiki v 2021-2023 godah. [Digital Platforms As a Tool for Transforming the World and Russian Economy in 2021-2023]. Jekonomika. Nalogi. Pravo [Economy. Taxes. Right]. 2021, no. 14(1),pp. 41-51. DOI : 10.26794/1999-849X 2021-14-1-41-51.

5. VTB Registrator. Oficial'nyj sajt. URL: https:/ /pos.vtbreg.ru/marketplace/ marketplace/market.html (accessed 14 May 2021).

6. KomarovA.V., Martjukova V.M. Neobanking kak napravlenie razvitija sovremennyh finansovyh tehnologij
[Neobanking As a Direction of Development of Modern Financial Technologies]. Vestnik universiteta [Bulletin of the University], 2020, no. 3, pp. 134-142.

7. Mesropjan V.R. Cifrovye platformy - novaja rynochnaja vlast'. URL: https://www.econ.msu.ru/science/ News.20180417134253_6961/(accessed 8 May 2021).

8. Moskovskaja Birzha. Oficial'nyj sajt. URL: https://finuslugi.ru/vklady/katalog/vse-vklady (accessed 14 May 2021).

9. Nikonec O.E., Popova K.A. Distancionnoe bankovskoe obsluzhivanie kak jelement jekosistemy sovremennogo banka [Remote Banking Services as an Element of the Ecosystem of a Modern Bank]. Vestnik Volzhskogo universiteta imeni V.N. Tatishheva [Bulletin of the V.N. Tatishchev Volga State University], 2020, vol. 2, no. 1, pp. 280-292.

10. OOO IA «Banki.ru». Oficial'nyj sajt. Slovar' bankovskih terminov. URL: https://www.banki.ru/ wikibank/transaktsiya/ (accessed 14 May 2021).

11. Pastushenko E.N., Zemcova L.N. Novelly pravovogo regulirovanija razvitija zashhity prav potrebitelej finansovyh uslug kak funkcii Central'nogo banka Rossijskoj Federacii v uslovijah cifrovoj jekonomiki [Novelties of Legal Regulation of the Development of Consumer Protection of Financial Services as a Function of the Central Bank of the Russian Federation in the Digital Economy]. Vestnik Saratovskoj gosudarstvennoj juridicheskoj akademi [Bulletin of the Saratov State Law Academy], 2020, no. 5 (136), pp. 228-234.

12. Petrova L. A., Kuznecova T. E. Cifrovizacija bankovskoj sistemy: cifrovaja transformacija sredy $\mathrm{i}$ biznes-processov [Digitalization of the Banking System: Digital Transformation of the Environment and Business Processes]. Finansovyj zhurnal [Financial Journal], 2020, vol. 12, no. 3, pp. 91-101. DOI: 10.31107/ 2075-1990-2020-3-91-101.

13. Razdorozhnyj K.B. Bank Rossii kak reguljator na rynke finansovyh tehnologij [The Bank of Russia as a Regulator in the Financial Technology Market]. Aktual'nye problemy rossijskogo prava [Actual Problems of Russian Law], 2021, vol. 16, no. 3, pp. 45-51. DOI: 10.17803/1994-1471.2021.124.3.045-051.

14. Samiev P.A., Zakirova V.R., Shvandar D.V. Jekosistemy i marketplejsy: obzor rynka finansovyh uslug [Ecosystems and Marketplaces: a Review of the Financial Services Market]. Finansovyj zhurnal [Financial Journal], 2020, vol. 12, no. 5, pp. 86-98. DOI: 10.31107/2075-1990-2020-5-86-98.

15. Sitnik A.A. Finansovye tehnologii: ponjatie i vidy // [Financial Technologies: the Concept and Types]. Aktual'nye problemy rossijskogo prava [Actual Problems of Russian Law], 2019, no. 6, pp. 27-31.

16. Slovari onlajn. Oficial'nyj sajt. Tolkovyj slovar' Dalja onlajn. URL: http://slovardalja.net/ word.php? wordid=26144 (accessed 14 May 2021). 
17. Smirnov E.N., Luk'janov S.A. Imperativy upravlenija global'nymi cifrovymi platformami [Imperatives of Managing Global Digital Platforms]. Upravlenec [Manager], 2020, vol. 11, no. 4, pp. 59-69. DOI: $10.29141 / 2218-5003-2020-11-4-5$.

18. Tropskaja S.S. Finansovyj rynok v uslovijah razvitija cifrovoj jekonomiki (finansovo-pravovoj aspekt) [Financial Market in the Conditions of Digital Economy Development (Financial and Legal Aspect)]. Finansovoe pravo [Financial Law], 2018, no. 8, pp. 28-33.

19. Federal'nyj zakon ot 10 ijulja 2002 goda № $86-F Z$ «O Central'nom banke Rossijskoj Federacii (Banke Rossii)». Rossijskaja gazeta [Russian Newspaper Dated], 2002, July 13 (no. 127).

20. Federal'nyj zakon ot 20 ijulja 2020 g. № 211-FZ «O sovershenii finansovyh sdelok s ispol'zovaniem finansovoj platformy» ["On Making Financial Transactions Using a Financial Platform”]. Rossijskaja gazeta [Russian Newspaper], 2020, July 24 (no. 162).

21. Federal'nyj zakon ot 22 aprelja 1996 goda № 39-FZ «O rynke cennyh bumag» [“'On the Securities Market"]. Rossijskaja gazeta [Russian Newspaper], 1996, April 25 (no. 79).

22. Federal'nyj zakon ot 23 dekabrja 2003 goda № 177-FZ «O strahovanii vkladov v bankah Rossijskoj Federacii»[On Insurance of Deposits in Banks of the Russian Federation]. Rossijskaja gazeta [Russian Newspaper], 2003, Dec. 27 (no. 261).

23. Federal'nyj zakon ot 7 avgusta 2001 g. № $115-\mathrm{FZ} « \mathrm{O}$ protivodejstvii legalizacii (otmyvaniju) dohodov, poluchennyh prestupnym putem, i finansirovaniju terrorizma» [Federal Law No. 115FZ Dated August 7, 2001 "On Countering the Legalisation of Illegal Earnings (Money Laundering) and the Financing of Terrorism"']. Rossijskaja gazeta [Russian Newspaper], 2001, Aug. 9 (no. 151).
24. Finansovaja platforma realizovana Gruppoj kompanij «INFINITUM». Oficial'nyj sajt [Financial Platform is Implemented by the "INFINITUM" Company Group. Official Website]. URL: https:// platform.finance/ (accessed 14 May 2021).

25. Anisina K.T., Badmaev B.G., Bit-Shabo I.V., et al. Finansovoe pravo $v$ uslovijah razvitija cifrovoj jekonomiki: monografija [Financial Law in the Conditions of Digital Economy Development]. Moscow, Prospekt Publ., 2019.

26. Bykanova N.I., Solovej Ju.A., Gordja D.V., Kon'shina L.A. Formirovanie jekosistem bankov v uslovijah cifrovizacii bankovskogo prostranstva [Formation of Bank Ecosystems in the Conditions of Digitalization of the Banking Space]. Jekonomika. Informatika. [Economy. Computer science], 2020, vol. 47, no. 1, pp. 91-100.

27. Accenture. Five ways to win with digital platforms. URL: https:/www.accenture.com/nl-en/ insight-g20-yea-digital-platforms\#blockhero (accessed 8 May 2021).

28. Daum T. Understanding digital capitalism. URL: http://dasfilter. com/gesellschaft/understandingdigital-capitalism-what-time-are-we-living-in-anintroduction (accessed 14 May 2021).

29. Schiller D. Digital capitalism stagnation and contention? URL: https://www.opendemocracy.net/ digitaliberties/dan-schiller/digital-capitalismstagnation-and-contention (accessed 8 May 2021).

30. Van Alstyne M., Parker G., Choudary S.P. Pipelines, Platforms, and the New Rules of Strategy. Harvard Business Review, April, 2016. URL: http:// ide.mit.edu/sites/default/files/publications/ Pipelines $\% 2$ C $\% 20$ Platforms $\% 2$ C $\% 20$ and $\% 20$ the $\% 20$ New\%20Rules\%20of\%20Strategy.pdf.pdf (accessed 8 May 2021).

\section{Information About the Author}

Denis E. Matytsin, Candidate of Sciences (Economics), Researcher, Department of Entrepreneurial Law, Civil and Arbitration Proceeding, Volgograd State University, Prosp. Universitetsky, 100, 400062 Volgograd, Russian Federation; Associate Professor, Department of Civil Law and Procedure, Volzhsky Branch of International Law Institute, Bolshevistskaya St, 7, 404106 Volzhsky, Russian Federation, ppagp@volsu.ru,dmatytsin@yandex.ru, https://orcid.org/0000-0002-4038-4032

\section{Информация об авторе}

Денис Евгеньевич Матыцин, кандидат экономических наук, научный сотрудник кафедры предпринимательского права, арбитражного и гражданского процесса, Волгоградский государственный университет, Университетский проспект, 100, 400062 г. Волгоград, Российская Федерация; доцент кафедры гражданского права и процесса, Волжский филиал Международного юридического института, ул. Большевистская, 7, 404106 г. Волжский, Российская Федерация, ppagp@volsu.ru,dmatytsin@yandex.ru, https://orcid.org/0000-0002-4038-4032 